Comunicación y género

ISSNe: 2605-1982

http://dx.doi.org/10.5209/CGEN.60251

\title{
Movimientos de mujeres para luchar contra la impunidad y el olvido: paralelismos y diferencias entre Ciudad Juárez (México) y Medellín (Colombia)
}

\author{
Javier Juárez Rodríguez ${ }^{1}$; Nora Elena Botero Escobar ${ }^{2}$
}

Resumen. El presente trabajo analiza desde una óptica comparativa el trabajo desarrollado por los movimientos sociales de mujeres en dos ciudad como Ciudad Juárez y Medellín, que, pese a su separación geográfica, presentan paralalismos significantes. Ambos municipios han estado históricamenete marcados por una violencia estructural contra las mujeres, perpetuada dentro de un sistema patriarcal hegemónico que, como analizamos, de forma constante ha solapado la violencia feminicida y misógina en el marco de inseguridda generalizada imperante en ambos lugares. La sororidad impulsada por mujeres juarenses y medellinenses han conseguido importantísimos avances en el trabajo de visibilización de esta realidad y en la exigencia de justicia a través de estrategias comunicativas y discursivas.

Palabras Clave: Patriarcado; México; Colombia; activismo; comunicación.

\section{Women's movements to fight against impunity and forgetting: parallels and differences between Ciudad Juárez (Mexico) and Medellín (Colombia)}

\begin{abstract}
This paper is aimed at analyzing, from a comparative lens, the work developed by female social movements in Ciudad Juárez and Medellín. Despite their geographical separation, these two cities present remarkable similarities. Both municipalities have historically been characterized by a strong presence of structural violence against women. As shown in our analysis, the hegemonic patriarchal system prevailing in these two cities has led to a climate of widespread insecurity and has contributed to the perpetuation of feminicidal and misogynist violences. The sorority promoted by the women of Ciudad Juarez and Medellín has achieved major advances towards visualizing this reality, as well as in pushing the demand for justice through communicative and discursive strategies.
\end{abstract}

Keywords: Translation; Patriarchy; Mexico; Colombia; activism; communication.

Sumario. 1. Introducción. 2. Metodología. 3. Desarrollo de la investigación. 3.1. Contextualización de la violencia en México y Colombia. 3.2. Estrategias discursivas desde el activismo de mujeres: diferencias y paralelismos entre Ciudad Juárez y Medellín. 3.3. Los movimientos de mujeres en Ciudad Juárez. 3.4. Los movimientos de mujeres en Medellín. 4. Conclusiones. 5. Bibliografía.

Cómo citar: Juárez Rodríguez, J.; Botero Escobar, N. E. (2018). Movimientos de mujeres para luchar contra la impunidad y el olvido: paralelismos y diferencias entre Ciudad Juárez (México) y Medellín (Colombia). Revista Comunicación y género, 1 (1) 2018, 113-126.

\footnotetext{
$1 \quad$ Universidad de Medellín

jjuarez@udem.edu.co

2 Universidad de Medellín

nebotero@udem.edu.co
} 


\section{Introducción}

Entre 1985 y 2014 más de 47.000 mujeres han sido asesinadas en México y alrededor de 4.000 permanecen en calidad de desaparecidas ${ }^{3}$. Sólo en la última década (20072017) más de 11.000 mujeres han sido ultimadas en la República, 1.100 de ellas en Ciudad Juárez, según los datos aportados por la Fiscalía de Chihuahua durante el desarrollo de la presente investigación, feminicidios que, en su mayoría, vienen ligados a una total impunidad ${ }^{4}$. En el caso de Colombia, la labor documental se hace más compleja aún a la hora de cuantificar las cifras de la violencia machista, ya que no fue hasta el año 2015, cuando los registros de Medicina Legal fueron sistematizados, es decir, antes de esta fecha, las cifras de muertes violentas de mujeres se archivaban sin establecer por qué fallecieron, quién las asesinó ni bajo qué circunstancias. En este sentido, a pesar de los avances legislativos conseguidos en los últimos ocho años para combatir y erradicar la violencia de género, y de la relativa mejora en materia de seguridad con la firma de los Acuerdos de Paz entre el Estado y las FARC, esta violencia sigue siendo una lacra social presente en la sociedad colombiana. Cada año alrededeor de 1.000 mujeres son asesinadas en Colombia, y cerca de 50.000 son violentadas sexualmente, según datos Oficiales de Medicina Legal. Centrándonos en Medellín, la capital antioqueña registró más de 1.900 agresiones sexuales en 2017, según datos de la Personería de Medellín. Antioquia es, lamentablemente, uno de los departamentos con mayores índices de violencia machista, como lo demuestra el hecho de que sólo en 2016, 126 mujeres fueron asesinadas, 40 de ellas en Medellín.

Aunque en espacios gerográficamente muy separados y en sociedades, al menos a priori, socialmente muy dispares, Ciudad Juárez y Medellín presentan inquietantes similitudes en relación tanto a la violencia misógina estructural como a la respuesta dada por mujeres contestatarias que decidieron plantarle cara a la injusticia y a la impunidad. Aunque, como se analiza en la presente investigación, las exigencias y reivindicaciones de estos colectivos presentan claras diferencias, marcadas por el contexto histórico y político de cada ciudad, no cabe duda de que estas presentan un eje común: la exigencia de memoria y justicia. Igualmente, la labor reivindicativa y de denuncia de estos colectivos formados y liderados por mujeres no ha sido fácil ni tampoco gratuita; tanto en Ciudad Juárez como en Medellín el activismo y la movilización pública de estas mujeres ha sido respondido como amenazas y violencia, como demuestra el hecho de que en la última década al menos un decena de activistas hayan sido amenazadas, agredidas y/o asesinadas en el Estado de Chihuahua, o que 94 activistas (hombres y mujeres) fueran asesinados en Antioquia solo entre 2010 y 2015, como denuncia el informe "Silenciados: el asesinato de activistas políticos en Colombia”, de la organización británica Justice for Colombia.

Si bien es cierto que ambos municipios han estado marcados por los altos índices de violencia y las disputas entre estructuras criminales por el control del narcotráfico, agudizado en el caso de Colombia con los hechos derivados del conflicto armado, la violencia contra las mujeres ha sido transversal y permanenente tanto en Ciudad

3 Datos obtenidos del Informe La violencia feminicida en México, aproximaciones y tendencias 1985-2014, editado por ONU, INMUJERES y SEGOB disponible en:

https://www.gob.mx/cms/uploads/attachment/file/84740/La_Vilencia_Feminicida_en_M_xico__ aproximaciones_y_tendencias_1985_-2014.pdf

4 Según datos aportados por el Instituto Nacional de las Mujeres (Inmujeres) en 2009, el 90\% de los feminicidios cometidos en México quedan impunes. 
Juárez como en Medellín. Por todo ello, cobra más importancia si cabe la presente investigación, a través de la cual se analizan las acciones y estrategias desarrolladas por estos colectivos mediante una labor investigativa basada en la etnografía y centrada en el análisis de dos organizaciones de mujeres referentes en Ciudad Juárez y Medellín como son: Nuestras Hijas de Regreso a Casa y Caminos de Esperanza Madres de la Candelaria.

\section{Metodología}

Con el fin de obtener una aproximación general a la temática investigada se abordaron enfoques de carácter cualitativo, exploratorio y descriptivo. En este sentido, la perspectiva cualitativa ayuda a comprender el fenómeno de estudio en su ambiente, mediante la observación participante activa, analítica y crítica para estudiar el contexto donde se producen los hechos objeto de estudio, es decir, en ambas ciudades.

Paralelamente hemos analizado las estrategias discursivas de dos colectivos, Nuestras Hijas de Regreso a Casa y Caminos de Esperanza Madres de la Candelaria, así como sus tácticas comunicativas para visibilizar su lucha ante los diferentes actores que ostentan el poder y convertirse, además, en interlocutores válidos política y socialmente. Junto a este análisis, se han realizado entrevistas propias que generan notoriedad y relevancia al trabajo, en este caso a activistas (madres e hijas de mujeres asesinadas o desaparecidas) de ambos colectivos.

\section{Desarrollo de la investigación}

\subsection{Contextualización de la violencia en México y Colombia}

Para analizar la evolución y las mutaciones de la violencia en México y Colombia a lo largo de los últimos lustros, resulta imprescindible desarrollar un ejercicio previo de contextualización histórica, que enmarque la violencia en general, y la violencia misógina en particular, en el seno de un sistema de poder patriarcal (Roselló, 2008), en el que sus actores hegemónicos, varones, han sellado históricamente pactos interclasistas e intergeneracionales para garantizar la continuidad de este sistema misógino estructural.

En ambos países, con sutiles diferencias, nos enfrentamos a un sistema que protege a agresores y asesinos, que se sienten respaldados por los actores dominantes y que se creen con todas las garantías para vulnerar los derechos de las mujeres y, en último extremo, agredirlas física y sicológicamente llegando, incluso, al feminicidio (Monárrez, 2002). El propio sistema y sus mallas de poder (Foucault, 1999) normalizan la violencia misógina contra las mujeres gracias a unos Estados que durante años hna demostrado activamente su desinterés y su indolencia ante estos hechos (Incháustegui, López 2011), siendo, incluso, condenado por organismos internacionales como la Corte Interamericana de los Derechos Humanos ${ }^{5}$ en el caso de México

5 La CIDH hacía pública en 2009 su sentencia por el "Caso González y otras Vs. México” donde condenaba al Estado México por los feminicidios del llamado caso “campo algodonero" cometidos en Ciudad Juárez. http:// www.corteidh.or.cr/docs/casos/articulos/seriec_205_esp.pdf 
o por organizaciones como Amnistía Internacional u OXFAM, en el caso de Colombia. Este papel negligente de las autoridades ha propiciado que durante los últimos años se haya multiplicado la tolerancia social a la violencia contra las mujeres y la impunidad en la comisión de estos crímenes. Nos enfrentamos ante todo un sistema que permite y protege este feminicidio estructural, potenciado por leyes, lenguajes y contenidos morales monistas y excluyentes (Cortina, 2009) que favorecen la persistencia del mismo. Como señala la investigadora Julia Monárrez nos situamos ante un fenómeno social normalizado por el Estado (Monárrez, 2000) lo que explica la complejidad del mismo y las dificultades existentes no solo para combatirlo, sino para denunciarlo y visibilizarlo como pasos necesarios para su futura erradicación.

El aumento desproporcionado de la violencia contra las mujeres documentado en Ciudad Juárez (México) a partir de 2008 vendrá enmarcado en un contexto histórico dominado por la guerra entre cárteles y un proceso de militarización, que lejos de procurar protección a las mujeres supuso un empeoramiento y un crecimiento desmedido de la violencia misógina y los feminicidios. La proliferación de desapariciones forzosas de niñas y mujeres, así como feminicidios sistemáticos, entre 2008 y 2013, vinieron unidos a un argumentario gubernamental basado en la vinculación directa de las víctimas con el crimen organizado, lo que, una vez más, redundaba en la culpabilización de las víctimas y la minimización de los hechos, como demuestra el hecho de que el propio alcalde Juárez, Enrique Serrano, afirmara públicamente en

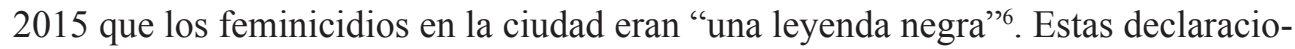
nes, contrstanm con la realidad, y es que solo entre 2010 y 2016 se documentaron 806 feminicidios de mujeres cuyas edades oscilarán entre 15 y 29 años en la ciudad fronteriza, según datos aportados la Red Mesa de Mujeres ${ }^{7}$. Decenas de mujeres y niñas han sido sistemática empleadas como arma de guerra de los actores masculinos predominantes, como elemento desechable por parte de la "masculinidad hegemónica" (Leatherman, 2013: 41).

La infiltración progresiva del crimen organizado entre los actores que conforman el poder ha consolidado la proliferación de los feminicidios sexuales como producto de pactos patriarcales entre varones que afianzan y fortalecen la confraternidad masculina (Amorós, 2004). En el caso concreto de los asesinatos sexuales seriales de mujeres en Ciudad Juárez, estos pactos entre varones conlleva, como señala la investigadora Rita Laura Segato (2004), actos comunicativos entre estructuras criminales de varones, incrustadas en el propio sistema patriarcal. Los feminicidios son, por lo tanto, la escenificación de este lenguaje específico entre estructuras misóginas y una realidad que hoy sigue presente en Ciudad Juárez.

Por su parte, la realidad de Colombia no puede entenderse sin analizar el conflicto armado que desde hace más de cinco décadas marca la historia colombiana. Numerosas organizaciones no gubernamentales y civiles han conseguido, gracias a un enorme esfuerzo, poner cifras y dimensionar la barbarie que el conflicto ha supuesto en relación a la violencia de género, los abusos y la impunidad por parte de todos los actores del conflicto. En este sentido, la investigadora Paula Guisao recordaba en el IV Seminario Internacional Políticas de la Memoria celebrado en 2011 en Buenos

\footnotetext{
Pérez, C. (20 de febrero de 2015). "Leyenda negra", fenómeno de los feminicidios en Juárez, dice el alcalde. Disponible en: http://www.jornada.unam.mx/2015/02/20/politica/018n2pol

7 Ávila, A. ( 31 de octubre de 2016) Asesinatos de mujeres en Ciudad Juárez, "La guerra sigue". Disponible en: https://desinformemonos.org/asesinatos-mujeres-ciudad-juarez-la-guerra-sigue/
} 
Aires que la "violencia sexual" ha sido una práctica generalizada en el conflicto armado colombiano, usada de manera sistemática por todas la partes: guerrilleros, paramilitares y miembros del Ejército y la Policía Nacional. Miles de mujeres y niñas han sido históricamente empleadas como "trofeos de guerra" y sus cuerpo utilizados, al igual que en Ciudad Juárez, como parte de un lenguaje específicos entre varones basado en la violencia sobre los cuerpos de las mujeres, ejercida, además, de forma "panóptica", es decir, al igual que en el caso de México, sin existir vínculos entre víctimas y victimarios y, nuevamente, la impunidad rodea estos crímenes de lesa humanidad (Juárez, 2017).

Centrándonos en Medellín, segunda ciudad colombiana en número de habitantes, desde los años 50 del siglo pasado ha sido lugar de asentamiento de campesinos, que por razones de la violencia producida por el conflicto en los campos, se han visto obligados a emigrar hacia las ciudades, paradójicamente para salvar sus vidas. Pero en lugar de eso, entran a engrosar los cordones de miseria que habitan en la periferia, formando parte de la espiral de violencia, tanto o más grave, de la que huyeron. Aunque la historia de Medellín ha estado unida al oro, a la actividad comercial, al café, a la industria, a la innovación, a los servicios públicos de calidad y al progreso, también está ligada, como ya mencionamos a la violencia, principalmente como resultado del narcotráfico, donde Pablo Escobar, aunque hoy muerto, sigue siendo su principal protagonista. Muy a pesar de los medellinenses, la ciudad se continúa relacionando con la droga y el miedo que Escobar, por su accionar violento, situó como noticia de primera plana en los medios de comunicación del mundo en la década de los 90 y en los primeros años del 2000.

Esta situación dota a la ciudad de Medellín de unas ciertas condiciones favorables para el surgimiento de actividades ilegales y la consecuente formación de bandas criminales, las mismas que ven en estas personas venidas del campo, la materia prima para garantizar su existencia, pues es de estos grupos sociales de donde salen, principalmente, los sicarios que luego van a estar al servicio de los capos del narcotráfico. Aunque actualmente, el fenómeno tiene otros matices gracias a las diferentes intervenciones del Estado, la violencia ha dejado y continúa dejando un número considerable de víctimas, donde las mujeres, altamente invisibilizadas, continúan aportando una gran proporción a las cifras oficiales y extraoficiales. Por ejemplo para el año 2016, según el Instituto Nacional de Medicina Legal, en Colombia, fueron asesinadas 902 mujeres por la mal llamada violencia intrafamiliar y 59.082 fueron víctimas de la violencia por razones de género, dentro de esta última cifra Medellín aporta 5.110 mujeres que denunciaron algún tipo de maltrato, donde el $64.88 \%$ fue causado por su pareja sentimental.

A pesar de estas cifras, lo más preocupante aún, es que dentro de dichos reportes no se habla de las mujeres, que aunque no son maltratadas por sus parejas, tienen que sufrir la violencia sicológica al tener que ver a sus familiares desaparecidos, torturados y/o asesinados. Estas cifras no se conocen, no se registran, pues en cierta forma no se valoran, por el contrario, estas mujeres, estas madres, en sus búsquedas incesantes e incansables, son calificadas por los empleados públicos a los que les corresponde atenderlas en sus justos requerimientos, como "viejas cansonas", como "desesperantes", tal y como denuncian las propias víctmas entrevistas.

Así las cosas, la ciudad de Medellín, al igual que Ciudad Juárez, se convierte en escenario para que las mujeres se organicen y luchen unidas para no solo contrarrestar el flagelo de la violencia, sino también compartir su dolor y encontrar razones 
suficientes para construir una nueva vida donde esa enorme tristeza sea más llevadera, ya no como víctimas sino como sobrevivientes. Bajo esta perspectiva se crean multiplicidad de grupos de mujeres en Ciudad Juárez y en Medellín que encontraron en su unión una forma de luchar contra la violencia, la invisibilización y hacer catarsis a su dolor.

\subsection{Estrategias discursivas desde el activismo de mujeres: diferencias y paralelismos entre Ciudad Juárez y Medellín}

Aunque, como ya hemos adelantado, los movimientos sociales conformados por mujeres en la exigencia de justicia y memoria tanto en Ciudad Juárez como en Medellín presentan paralelismos, desarrollando un análisis cualiatitivo de sus discursos públicos podemos localizar importantes matices en cuanto a los contenidos de sus exigencias y la finalidad de sus reivindicaciones. En este sentido, en el caso de Ciudad Juárez los movimientos sociales conformados por mujeres, sobre todo a partir de la década de los 90, cuando las informaciones periodísticas sobre los feminicidios sexuales comienzan a tener una difusión internacional y surgen investigaciones científicas contrastadas de la mano de investigadoras como Julia Estela Monárrez y más tardes Rita Laura Segato, entre otras, impulsarán campañas y estrategias discursivas basadas en la búsqueda de la visibilización de los numerosos casos de feminicidios sexuales, así como las desapariciones sistemáticas de niñas y mujeres. Es decir, Asociaciones como Voces Sin Eco, Casa Amiga, Nuestras Hijas de Regreso a Casa o Justicia para Nuestras Hijas (esta última en la ciudad de Chihuahua), aportarán exigencias y estrategias comunicativas transversalizadas por un enfoque de género y cimentadas en la exigencia de Justicia.

Sin embargo, en el caso medellinense, los movimientos liderados por mujeres, como el colectivo Caminos de Esperanza Madres de la Candelaria o Mujeres Caminando por la Verdad, no centrarán sus reivindicaciones únicamente en los casos de desapariciones forzosas de mujeres y niñas, sino que ampliarán este espectro también a hombres víctimas del conflicto aunque, al igual que en Juárez, serán las mujeres (madres, hijas o hermanas de las víctimas) las que liderarán las campañas de activismo social así como las estrategias comunicativas y discursivas. Centrándonos en el caso colombiano, el conflicto interno ha marcado a través del dolor y la violencia la piel del país, especialmente en mujeres y niñas que han sido históricamente las grandes obviadas de los ámbitos de poder en Colombia, pese a sufrir en primera persona la vulneración de sus derechos por parte de los actores masculinos del conflicto. El uso y abuso de su cuerpo, empleado como arma de guerra ha sido una constante, ligada, además a una total impunidad y un preocupante silencio buscando la invisibilización.

Al igual que sucediera en Ciudad Juárez, las mujeres medellinenses fueron “obligadas" a convertirse en activistas ante un Estado ineficaz, cuando no cómplice, y unirán sus fuerzas y objetivos no ya solo en la reivindicación de derechos para las mujeres, sino en la construcción de una nueva Colombia desde la justicia, la memoria y la reconciliación con una participación femenina activa. De este modo, tomarán fuerza los movimientos impulsados y liderados por mujeres, que, como señala la investigadora Lola Luna, pasarán a convertirse en "movimientos por la supervivencia".

Pese a las diferencias marcadas, los movimientos activistas de mujeres tanto en Ciudad Juárez como en Medellín presentan notables paralelismos desde un análisis discur- 
sivo y estratégico. En este sentido, la investigación desarrolló su trabajo de campo tanto en Ciudad Juárez como en Medellín donde, a través de la observación participante, se llevó a cabo un análisis de las acciones y las estrategias comunicativas impulsadas por dos organizaciones referentes del activismo liderado por mujeres a lo largo de las últimas dos décadas: Nuestras Hijas de Regreso a Casa (Ciudad Juárez) y Caminos de Esperanza Madres de la Candelaria (Medellín). En este sentido, se realizaron entrevistas a las portavoves de ambos movimientos (Marisela Ortiz y Teresita Gaviria, respectivamente) así como a mujeres integrantes de las dos organizaciones (Rovira, 2012). Ambas organizaciones diseñaron a lo largo de últimos años una efectiva estrategia comunicativa y un plan de actividades basado en la búsqueda de relevancia, difusión e internacionalización de la problemática, haciendo de la comunicación la base de sus denuncias. Tal y como señala la activista Marisela Ortiz, fundadora de la Nuestras Hijas de Regreso a Casa, exiliada como consecuencia de las amenazas de muerte recibidas:

"En nuestro caso tuvimos que convertirnos en comunicadoras, relacionistas públicos, activistas (...) uno de nuestros objetivos primarios era dar a conocer lo que estaba ocurriendo en Ciudad Juárez, aletar a la comunidad juarense de que todo aquello que decían de las jovencitas asesinadas sobre que eran prostitutas, drogadictas o que llevaban una doble vida no era cierto, $\mathrm{y}$ al mismo tiempo alertar a la comunidad internacional para que exigiera al Gobierno colombiano que actuara ante tanta impunidad" (Ortiz, Marisela. Entrevista personal realizada el 4 de mayo de 2018).

El mensaje directo sobre los feminicidios y desapariciones de mujeres tanto de Marisela Ortiz como de Norma Andrade (Co-fundadora de Nuestras Hijas de Regreso a Casa) obtendrá gran repercusión en medios y organismos internacionales, llegando incluso al Parlamento Europeo. Sin embargo, estos avances en materia de visibilización e internacionalización de la problemática no fueron gratuitos: venieron seguidos por una campaña de difamación contra sus impulsoras, además de actos intimidatorios contra su persona y familia, que fueron desde las amenazas hasta las agresiones físicas, lo que les obligó a dejar la ciudad en 2010 y 2011, respectivamente. Algo, que, lastimosamente, también se dará en el caso de Madres de la Candelaria, personalizando estas amenazas y agresiones sobre la figura de su portavoz, Teresita Gaviria.

Como señalaba Marisela Ortiz en la entrevista realizada, la situación extrema de injusticia e indefensión que sufrieron estas mujeres les "obligó" a convertirse en periodistas y comunicadoras sin apenas formación ni recursos. Su labor comunicativa y contestataria consiguió que algunas de sus reivindicaciones formaran parte de la agenda pública. Las nuevas redes sociales e internet supusieron un paso adelante importantísimo en su búsqueda de visibilización. En este sentido, para Caminos de Esperzna Madres de la Candelaria, las nuevas tecnologías de la información son un bastión fundamental, potenciando una comunicación horizontal con la ciudadanía y los medios de comunicación, además de potenciar la interactuación. En este sentido, Teresita Gaviria, Portavoz del colectivo, reconoce que:

"Ante la falta de recursos hemos tenido que hacer de todo y aprender a hacer cosas que jamás nos habiamos planteado. Gracias a nuestras reivindicaciones públicas, nuestras repercusión en las redes y en los medios, establecimos una 
comunicación directa con los integrantes de los grupos armados y los actores del conflicto" (Gaviria, Teresita. Entrevista personal realizada el 15 de junio de 2017).

\subsection{Los movimientos de mujeres en Ciudad Juárez}

Como ya hemos adelantado, la inacción gubernamental, sumada a la cadena de acoso y despestrigio dirigida históricamente contra las propias víctimas (a las que han acusado en reiteradas ocasiones de llevar una doble vida o provocar su propia violación y asesinato por caminar solas por la noche o vestir provocativamente) y sus familias (fundamentalmente las madres) generaron en el caso de Ciudad Juárez la reacción de éstas últimas, que en un ejercicio de valentía y rebeldía ante un sistema injusto, forjarán un movimiento de sororidad, entendido, como apunta la antropóloga Marcela Lagarde, como una solidaridad específica entre mujeres (Lagarde, 2012).

Una de las mujeres que simboliza esta lucha contestaria ante la infamia gubernamental es Ramona Morales, integrante de Nuestras Hijas de Regreso a Casa, quien ha trabajado durante años junto a Marisela Ortiz para denunciar las mentiras de Estado fabricadas tras el secuestro y feminicidio de su hija en 1995, Silvia Elena Morales Rivera, de sólo 15 años. Ramona Morales ha denunciado en reiteradas ocasiones que el propio Francisco Barrio (Gobernador del Estado de Chihuahua) le aseguró, tras entregarle el cuerpo de su hija, que Silvia Elena llevaba una doble vida, frecuentaba por las noches los antros y vestía de forma provocativa para tentar a los hombres, lo que causó, según las autoridades, su secuestro y posterior feminicidio. Pese a ello, Ramona y otras madres víctimas de los mismos argumentos misóginos, no aceptaron la versión aportada por las autoridades y decidieron movilizarse y trabajar conjuntamente en la exigencia de justicia. "Las madres nos organizamos y nos unimos. Somos hermanas del mismo dolor" (Morales, Ramona. Entrevista personal realizada en octubre de 2016)

Durante años las autoridades mexicanas han repetido de forma sistemática argumentos ficticios. En lugar de activar los mecanismos propuestos, y en muchos casos previstos para su erradicación de esta lacra, optaron por una estrategia más sencilla: la culpabilización de las víctimas. La investigadora Tania Sordo (2011) denuncia en este sentido como ante la ineficacia gubernamental, las autoridades conformaron estrategias comunicativas para argumentar que son ellas, las propias víctimas, las que provocan los delitos por no cumplir con las imposiciones sociales, es decir, que ellas son las responsables de sus secuestros, violaciones, torturas y asesinatos porque iban vestidas de una determinada forma o porque caminaban solas.

El trabajo de sororidad emprendido por algunos colectivos desde la década de los 90 hasta hoy ha sido sustentado en denuncias públicas potentes que, en algunos casos, han logrado un destacable eco nacional e, incluso, internacional, potenciando la presión de organismos defensores de los derechos humanos sobre los diferentes estamentos gubernamentales para exigir respuestas ante los hechos denunciados y contrarrestar, de este modo, los mensajes y los argumentos oficiales. Como señala la investigadora Julia Monárrez los actores masculinos hegemónicos explicaron en un primer momento su propia historia sobre los feminicidios, señalando que las víctimas eran secuestradas y asesinadas porque llevaban una "doble vida" o porque provenían de familias desintegradas, cargando además contra activistas que exigían jus- 
ticia argumentando que lo hacían con fines únicamente lucrativos (Monárrez, 2010). Sin embargo, el ejercicio de sororidad conjunta entre mujeres consiguió reescribir la historia a base de esfuerzo, movilizaciones y hermandad ante las infamias y las manipulaciones gubernamentales denunciadas ya desde los años 90 .

La guerra entre estructuras criminales lideradas por el Cártel de Juárez y el de Sinaloa en la ciudad y su entorno, agudizada a partir de 2008, vino acompañada por un multiplicación de los feminicidios y desapariciones de mujeres y una ausencia total de previsión y políticas de choque contra el terrorismo machista pese a los precedentes ya documentados. Las autoridades, lejos de afrontar esta realidad y declarar la alerta de género ${ }^{8}$, repitieron esquemas y estrategias enfocadas a la minimización de los hechos y, de nuevo, la culpabilización de las propias víctimas, en esta ocasión englobando los crímenes feminicidas dentro de la violencia genérica existente entre estructuras delincuenciales que sufría la ciudad como consecuencia de la proliferación y el empoderamiento progresivo del crimen organizado, justificando de este modo los asesinatos o desapariciones de las jóvenes por su supuesta pertenencia a redes delictivas sin prueba ni soporte documental alguno. Sólo entre 2008 y 2015 se documentarán más de 1.000 feminicidios y las desapariciones forzosas de más de un centenar de mujeres, gran parte de ellas menores de edad. Pese a ello, el alcalde del municipio, lejos de afrontar esta realidad y admitir la gravedad de los hechos, se limitó señalar en 2015 que los feminicidios y desapariciones de mujeres en Ciudad Juárez son "una leyenda negra".

Ante esta situación algunas madres se negarán a aceptar las cadena de argumentos falsos y/o manipulados de las autoridades e intensificarán una unión intergeneracional con un objetivo común: trabajar juntas contra un sistema patriarcal injusto y reivindicar memoria y justicia. Las mujeres dejan a un lado sus posibles discrepancias o diferencias para emprender juntas una lucha de mujeres en pos de la justicia y contra la impunidad, basada en el respeto y el apoyo mutuo entre ellas para enfrentarse al patriarcado.

Este choque contra quienes ostentan el poder y su cuestionamiento de las reglas marcadas por los actores masculinos hegemónicos no fue gratuita, y vino acompañada por una progresiva campaña de acoso, amenazas y agresiones contra las propias madres de las jóvenes secuestradas y/o asesinadas, convertidas ya en activistas. Numerosas familias fueron, víctimas de amenazas y acoso por sus denuncias, y algunas madres, como Irma Monreal (madre de Esmeralda Herrera, joven cuyos restos fueron localizados en 2001 en un campo algodonero) denunciará incluso que los casos no son resueltos porque "los que matan a las mujeres no se pueden investigar a sí mismos"10. Una denuncia secundada por Josefina González, madre de Claudia Ivette González, secuestrada el 10 de octubre de 2001 en Ciudad Juárez frente a la maquila en la que trabajaba. Pese a sus denuncias públicas, implicando a policías en la desaparición de su hija y aportando datos y pruebas, los hombres presuntamente

8 Conjunto de acciones gubernamentales de emergencia para enfrentar y erradicar la violencia feminicida y/o la existencia de un agravio comparado que impida el ejercicio pleno de los derechos humanos de las mujeres, en un territorio determinado (municipio o entidad federativa. (Artículo 22 de la Ley de Acceso).

9 Pérez, Ciro. (19 de febrero de 2015) “Leyenda negra”, los feminicidios en Ciudad Juárez, dice el alcalde". La Jornada.http:/www.jornada.unam.mx/ultimas/2015/02/19/feminicidios-en-ciudad-juarez-son-una-201cleyenda-negra201d-edil-8542.html

10 Villalpando, Rubén. (20 de febrero de 2004). Familiares de mujeres asesinadas denuncian amenazas policiales. La Jornada. http://www.jornada.unam.mx/2004/02/20/045n1 soc.php?printver=1\&fly=1 
implicados jamás fueron investigados. Un hecho que se ha repetido a lo largo de las últimas dos décadas, donde las propias madres han tenido que exponer sus vidas para obtener datos sobre el paradero de sus hijas o sus victimarios.

Solo la acción conjuntas estas mujeres, unidas en hermandad ante la adversidad, conseguirá avanzar en una visualización básica para la posible erradicación de la problemática. En este sentido, otra estrategia empleada por estas mujeres ha sido la de las movilizaciones y acciones públicas, una iniciativa que nació en la década de los 90 de la mano de la familia González-FloresPaula Flores, madre de Sagrario González Flores, joven de 17 años asesinada en abril de 1998, y Guillermina, su hija y hermana de Sagrario, fueron pioneras en poner en marcha de forma organizada la acción conjunta de mujeres, aglutinando a algunas familias en su exigencia de respuestas y justicia. La falta de medios y de apoyo vino, además, acompañada por una estrategia de acoso, menosprecio y ataques permanentes por parte de empleados del gobierno (Washington, 200). Voces sin Eco, fundada por ambas, fue la primera muestra de insumisión de las familias ante las mentiras gubernamentales y su puesta en marcha supone, como avanza la investigadora Martha Estela Pérez (2005), un primera respuesta organizada de mujeres dirigida por ellas mismas, una tarea compleja ante la ausencia de recursos y las fuerzas desiguales de los actores, pero que consolidará un primer foco de denuncia y exigencia frente a al poder establecido. Entre las medidas impulsadas por esta organización, destaca la puesta en marcha de un campaña de denuncia pública de la vulneración de los derechos de las mujeres y la comisión de feminicidios sexuales a través de la pintuta de cruces negras sobre fondo rosa en todo el municipio y su entorno, una medida que aún hoy, más de dos décadas despupes, persiste en numerosas zonas de Ciudad Juárez y su Valle. Junto a ello, durante numerosos años las mujeres integrantes de estos colectivos han organizado marchas y concentraciones públicas que han logrado una importante repercusión En este sentido, Nuestras Hijas de Regreso a Casa organizó durante más de un lustro plantones frente a la Fiscalía llevados a cabo el tercer martes de cada mes como gesto de protesta, logrando una gran acogida entre medios y periodistas, que, conocedores del evento, daban cobertura al mismo. Más recientemente, moviemientos como el Comité de Madres de Mujeres Desaparecidas han continuado con esta estrategia con acciones que lograron una importante repercusión internacional, como la marcha organizada en enero de 2013 en algunas de estas mujeres recorrieron a pie los 370 kilómetros que separan Juárez de la Capital para exigir acciones al Gobernador, César Duarte.

\subsection{Los movimientos de mujeres en Medellín}

Por su parte analizando la situación en Medellín (Colombia), ante la sistemática invisibilización de las mujeres como víctimas de la vilencia sicológica, la ciudad se convierte también en un espacio para la lucha, por lo cual se comienzan a generar grupos, en su gran mayoría de mujeres.

Uno de estos grupos surgidos en Medellín fue la Asociación Caminos de Esperanza Madres de la Candelaria. Este colectivo nació en marzo de 1999 como una organización que reunía a un grupo de familiares de policías y soldados secuestrados por la guerrilla y que no encontraban eco en el gobierno para su liberación. Con el paso de los años y agudización del conflicto, se fueron sumando más personas, en su mayoría madres, pero no solo víctimas de la guerrilla, sino también de los paramili- 
tares y hasta del mismo gobierno, representado por el Ejército y la Policía. La Asociación fue creciendo exponencialmente y con ello, adquiriendo mayor relevancia y visibilidad, toda vez, que estas amas de casa eminentemente campesinas y algunas analfabetas, se comenzaron a empoderar y a entender que unidas podían hacer mayor presión para que sus denuncias fueran escuchadas, fueran tenidas en cuenta (Giraldo, Toro, Estrada y Mejia, 2015:17).

$\mathrm{Su}$ lucha ha sido tan representativa e importante, que cuando ellas comenzaron a marchar y realizar sus plantones frente a una de las iglesias insignes de la ciudad de Medellín, como es la de La Candelaria, ubicada en el Parque Berrío, en pleno corazón de la ciudad, la desaparición forzada no estaba tipificada como delito en Colombia. No fue hasta el 6 de julio del año 2000 cuando sería aprobada la Ley 589, la cual reconoce la desaparición forzada como delito se permitió, por lo menos jurídicamente, que estas madres comenzaran la búsqueda de sus seres queridos.

En la Asociación estas víctimas, hoy sobrevivientes del conflicto, son escuchadas, formadas, orientadas jurídica y psicosocialmente. Allí en una oficina de 30 metros cuadrados emplazada en un viejo edificio del centro de Medellín, estas luchadoras encuentran el coraje y la valentía de otras sobrevivientes, como su líder y directora Teresita Gaviria; y, de Ana María Olarte, María Dolores Londoño, María Guillermina Zapata entre muchas más, para sobrellevar su pena, para encontrar un camino de esperanza.

En la conmemoración de los 18 años de la Asociación, su directora Teresita Gaviria, presentó unas cifras desgarradoras: a marzo de 2017 tienen registrados en su organización, 1.177 desaparecidos, de los cuales han encontrado los restos de 110; aún quedan 1.067, y es por ellos que continúan trabajando incansablemente. Cualquier pista, cualquier indicio, sirve. Ellas, valientes, determinadas, van tras de ello, aunque les toque madrugar para llegar al Palacio de Justicia y poder entrar al recinto donde se realiza el juicio del victimario de su ser querido, o si no pueden entrar, verlo pasar y poder decirle que les aporte una pista de dónde están enterrados sus desaparecidos; ir a la cárcel para hablar con ellos cara a cara o hacer antesala a un Concejal para que les sirva de mediador ante un servidor público que tenga algún dato que les ayude a encontrarlos. Es una lucha incesante, porque, como ellas mismas dicen, esos 1.067 desaparecidos las están esperando.

Pero no solo la labor de la Asociación se suscribe a esto, hay otras funciones del colectivo que las dignifican y les dan alto reconocimiento social. Aunque no son todas y todos, si una alta proporción de las personas que llegan a la Asociación Caminos de Esperanza Madres de la Candelaria, hacen parte de los cordones de miseria que se asientan en la periferia de la ciudad, son personas pobres con muchas falencias, no solo de carácter económico sino también social y sicológico. Por esto aquí el colectivo desarrolla una importante función social, apelando a las mismas cifras entregadas por directora Teresita Gaviria en la ceremonia ya señalada, el colectivo cuenta con 826 mujeres agremiadas, de las cuales ya están formadas 127, ellas han hecho cursos de artes manuales que luego les sirve para generar una forma de sustento a través de una micro-empresa, también han podido terminar su primaria, lo que les ha dado otra perspectiva de la vida, pues desarrollaron su expresión verbal y escrita, permitiéndoles mejorar su proceso de búsqueda de esos seres queridos que hace años que no ven y que la violencia visceral les arrebató. 


\section{Conclusiones}

Los colectivos de mujeres tanto en Ciudad Juárez como en Medellín se han consolidado a lo largo de los últimos años como fuente de contrapoder e interlocutores válidos reconocidos socialmente, cuyo accionar ha permitido develar realidades que de otra forma continuarían ocultas.

Si bien es cierto que la historia reciente de ambas ciudades presentan paralelismos, como se analiza en el artículo, las reivindicaciones y los mensajes articulados por las asociaciones analizadas difieren en sus contenidos, pero coinciden en su objetivo y finalidad última: la exigencia de justicia, memoria y reparación. En este sentido, tras la investigación llevada a cabo en México y Colombia, evidencia que las estrategias comunicativas y discursivas de estos colectivos han sido la espina dorsal de los logros alcanzados hasta el momento. Haciendo de la necesidad virtud, estas activistas han conseguido, sin apenas recursos ni formación, internacionalizar sus exigencia y dar a conocer aspectos que, aunque locales, afectan a las mujeres mundialmente.

Hoy más que nunca se hace necesaria y urgente la solidaridad y la acción internacional en apoyo a la lucha y las reivindicaciones de estas mujeres, así como la implicación y la participación directa de organismos internacionales para frenar la impunidad. En el caso de Ciudad Juárez, los feminicidios y las desapariciones forzosas de mujeres no son, como apuntan las autoridades, una leyenda negra, ni un estigma sobredimensionado, sino una triste y compleja realidad. Cada mujer secuestrada, cada niña desaparecida es la antesala de una historia rota, el prólogo de una familia desesperada y el inicio de una cadena de ilusiones truncadas. Los feminicidios son la expresión final de la cultura misógina del odio, la muestra del fracaso de una sociedad que sólo desde la unidad, la solidaridad y, sobre todo, la educación en valores feministas, conseguirá superar esta lacra. Por su parte, Colombia en general y Medellín en particular afrontan un etapa crucial para la superación de la violencia del conflicto armado. A pesar de que, como hemos pormenorizado, las exigencias de los colectivos medellinenses no se han centrado únicamente en la búsqueda de mujeres desparecidas, sino que amplían estas denuncias a personas víctimas del conflicto (hombres y mujeres), no cabe duda de que la violencia misógina, tanto durante los años más beligerantes del conflicto como en la actualidad, sigue afectando a miles de mujeres y supone, por ello, uno de los ejes permanentes de actuación de estos colectivos.

Para finalizar es fundamental anotar las coincidencias existentes entre la cultura mexicana y la colombiana, ambas marcadas por la violencia y cimentada en principos e imaginarios machistas y misóginos, algo que queda patente en el ámbito de la comunicación y el lenguaje, y en lo que investigadoras y, como no, activistas de estos colectivos están trabajando para su erradicación.

\section{Bibliografía}

Amorós, C. (1994) Feminismo: Igualdad y diferencia. Capítulo I. México. PUEG-Programa Universitario de Estudios de Género- Universidad Nacional Autónoma de México.

Ávila, A. (31 de octubre de 2016) Asesinatos de mujeres en Ciudad Juárez, "La guerra sigue".

Disponible en: https://desinformemonos.org/asesinatos-mujeres-ciudad-juarez-la-guerrasigue/ 
Boletín Diciembre de 2016. Instituto Nacional de Medicina Legal y Ciencias Forenses. Recuperado de: http://www.medicinalegal.gov.co/boletines-estadisticos-mensuales el 3 de febrero de 2017

Castells, M. (2008). Comunicación, poder y contrapoder en la sociedad red II.Telos: Cuadernos de comunicación e innovación. (75). P.p. 11-23.

Castells, M.(2009). Comunicación y poder. Madrid. Alianza Editorial. P. 65, 78 y 79.

Cortina, A. Ética de la razón cordial: Educar en la ciudadanía en el siglo XXI. España: Nobel. 2009

Foucault, M. (1999). Las mallas del poder, en Estética, ética y hermenéutica. vol. III, trad. Ángel Gabilondo, Barcelona: Paidós.

García, A. (6 de diciembre de 2011). Activistas juarenses, blanco del crimen organizado. Proceso. Disponible en: http://www.proceso.com.mx/?p=290281

Giraldo Lopera, M.L., Toro Tamayo, L.C., Estrada Sierra, A. y Mejía Acevedo, V. (2015) Proyecto Museográfico Escuchar, Guardar, Abrazar: El archivo vivo de la Asociación Caminos de Esperanza Madres de la Candelaria. Medellín: Beca de Investigación sobre Procesos museográficos, Convocatoria Pública 2015 Arte y Cultura para la Vida de la Secretaría de Cultura Ciudadana de Medellín.

Guillén, A. (1991). Técnica de la desinformación (al servicio de la clase dominante). Madrid. Fundación Anselmo Lorenzo. P. 40.

Incháustegui, T., López, M. (Coord.). (2011). Feminicidio en México: Aproximación, tendencias y cambios 1985-2009. México. Entidad de las Naciones Unidas para la Igualdad de Género y el Empoderamiento de las Mujeres; Instituto Nacional de las Mujeres; Comisión Especial para conocer y dar Seguimiento Puntual y Exhaustivo a las Acciones que han emprendido las Autoridades Competentes en relación a los Feminicidios registrados en México. P. 17.

Juárez, J. (2017). Sororidad. Mujeres deconstruyendo los códigos y lenguajes patriarcales existentes tras los feminicidios de Ciudad Juárez. México: Universidad de Medellín. Colombia.

Lagarde, M. (2011) Sinergia por nuestros derechos humanos ante la violencia contra las mujeres en México, España y Guatemala en Lagarde, Marcela; Valcárcel, Amelia (Coord) Feminismo, género e igualdad. Madrid. Pensamiento Iberoamericano. AECID.

Lagarde, M. (2012). El feminismo en mi vida: Hitos, claves y topías. México. Inmujeres. P. 34.

Leatherman, J. (2013). Violencia sexual y conflictos armados. España. Ediciones Bellaterra. P. 41.

Ley 589 del 6 de julio de 2000. Consultada en: http:/www.alcaldiabogota.gov.co/sisjur/ normas/Norma1.jsp? $\mathrm{i}=14507$

Monárrez, J. (2009). Peritaje sobre Feminicidio Sexual Sistemático en Ciudad Juárez Presentado ante la Corte Interamericana de Derechos Humanos. Santiago de Chile. P. 33. Disponible en: http://www.corteidh.or.cr/docs/casos/expedientes/Mon\%C3\%A1rrez.pdf

Monárrez, J. (2002). "Feminicidio Sexual serial en Ciudad Juárez: 1993-2001”. Debate Feminista. Año 12, Vol. 25. Abril de 2002. P.p. 279-305.

Monárrez, J. (2000). "La cultura del feminicidio en Ciudad Juárez, 1993-1999”. Ciudad Juárez, México. Revista Frontera Norte. Enero-Junio 2000. Volumen 12, número 23. P.p. 87-117.

Monárrez, J. (2010). Las diversas representaciones del feminicidio y los asesinatos de mujeres en Ciudad Juárez, 1993 - 2005, en Cervera, Luis, Fuentes, César; Monárrez, Julia; Rodolfo Rubio (Coord.). Violencia contra las mujeres e inseguridad ciudadana en Ciudad Juárez, Vol. II. Miguel Ángel Porrúa Editores. Página 33. 
Pérez, C. (19 de febrero de 2015) "Leyenda negra", los feminicidios en Ciudad Juárez, dice el alcalde. La Jornada. Disponible en: http:/www.jornada.unam.mx/ultimas/2015/02/19/ feminicidios-en-ciudad-juarez-son-una-201 cleyenda-negra201d-edil-8542.html

Pérez, M. (2005). Las Organizaciones No Gubernamentales en Ciudad Juárez y su lucha contra la violencia de género. Noesis, Revista de Ciencias Sociales y Humanidades. Volumen 15. Número 18. Julio-Diciembre 2005. México: Instituto de Ciencias Sociales y Administración. Pp. 147-167.

Ravelo, P. (2008) El fenómeno del feminicidio: Una propuesta de recategorización. Centro de Investigaciones y Estudios Superiores en Antropología Social (CIESAS). México.

Roselló, E. (2008) La imagen estereotipada de la mujer víctima de la violencia de género en la prensa escrita: violencia simbólica o estructural en García, Antonio; Núñez, Sonia; Pérez-Amat Ricardo. Comunicación, identidad y género. Volumen 2. Madrid: Editorial Fragua. P. 584.

Rovira, G. (2012) Movimientos sociales y comunicación: la red como paradigma, En Revista Análisis, (45) Bogotá, pp. 92-96.

Segato, R. L. (2004). Territorio, soberanía y crímenes de segundo Estado: la escritura en el cuerpo de las mujeres asesinadas en Ciudad Juárez. Brasilia. Departamento de Antropología Universidad de Brasilia. P. 11.

Sordo, T. (2011). "Ella se lo buscó: Estereotipos de género en el Estado mexicano: Sentencia Campo Algodonero". XV Premio SIEM de Investigación feminista Concepción Gimeno de Flaquer. Universidad de Zaragoza. P.3.

Torrea, J. (2011). Juárez en la sombra: Crónicas de una ciudad que se resiste a morir. Madrid, España: Editorial Aguilar.

Villalpando, R. (20 de febrero de 2004). Familiares de mujeres asesinadas denuncian amenazas policiales. La Jornada. Disponible en: http://www.jornada.unam. $\mathrm{mx} / 2004 / 02 / 20 / 045 \mathrm{n} 1$ soc.php?printver=1\&fly=1

Villalpando, R. (28 de marzo de 2010) Falló el Operativo Conjunto Chihuahua, coinciden diversos sectores sociales. La Jornada, p.7. Disponible en: http://www.jornada.unam. $\mathrm{mx} / 2010 / 03 / 28 /$ politica/007n1pol

Washington, D. (2005). Cosecha de Mujeres: Safari en el desierto mexicano. Barcelona: Océano. 